\title{
Hydrothermal Synthesis of Hydrangea-Like F-Doped Titania Microspheres for the Photocatalytic Degradation of Carbamazepine under UV and Visible Light Irradiation
}

\author{
Miaomiao Ye, Yulong Yang, Yan Zhang, Tuqiao Zhang, and Weiyun Shao \\ Institute of Municipal Engineering, Zhejiang University, Hangzhou 310058, China \\ Correspondence should be addressed to Weiyun Shao, shaowy@zju.edu.cn
}

Received 12 September 2011; Accepted 23 October 2011

Academic Editor: Somchai Thongtem

Copyright (C) 2012 Miaomiao Ye et al. This is an open access article distributed under the Creative Commons Attribution License, which permits unrestricted use, distribution, and reproduction in any medium, provided the original work is properly cited.

\begin{abstract}
Hydrangea-like F-doped $\mathrm{TiO}_{2}$ microspheres have been synthesized on a large scale by a simple hydrothermal process using potassium titanium oxalate as the titanium source, ammonium fluoride and hydrogen peroxide as the etchant. The photocatalytic activities were evaluated using carbamazepine as the target organic molecule under UV and visible light irradiation. Structural characterization indicates that the hydrangea-like $\mathrm{TiO}_{2}$ microspheres, with an average diameter of $2.80 \mu \mathrm{m}$, are composed of numerous anatase $\mathrm{TiO}_{2}$ petals. Moreover, it is found that both the $\mathrm{NH}_{4} \mathrm{~F}$ and $\mathrm{H}_{2} \mathrm{O}_{2}$ dosages have important effects on the formation of the hydrangea-like structures. In addition, photocatalytic experiments show that the hydrangea-like $\mathrm{TiO}_{2}$ microspheres calcined at $500^{\circ} \mathrm{C}$ exhibit high photocatalytic efficiency under both UV and visible light irradiation. The enhanced photocatalytic activity can be attributed to the successful fluorine doping, good crystallinity, and the unique nanostructures.
\end{abstract}

\section{Introduction}

Heterogeneous photocatalysis using nanosized $\mathrm{TiO}_{2}$ catalyst under ultraviolet light illumination is an efficient method for the purification of wastewater [1-3]. However, a major barrier to the widespread use of $\mathrm{TiO}_{2}$ as photocatalyst is its relatively large optical band gap $\left(E_{g}=3.2 \mathrm{eV}\right)$, which limits its photoresponse to visible light $[4,5]$. To overcome this limitation, approaches such as mental (or anion) doping, nonmental (or cations) doping, and compositing with other semiconductors have been developed [6, 7]. Among them, it has been found that fluorine doping is the most effective process as it not only can promote the activity of $\mathrm{TiO}_{2}$ by slowing down the recombination of photogenerated electrons and holes [8-10] but also can induce a visible-light-driven photocatalysis by the creation of oxygen vacancies [11, 12].

On the other hand, in a practical photocatalytic process, it is very difficult to separate and recover these finely powdered $\mathrm{TiO}_{2}$ from a solution. Recently, three-dimensional (3D) hierarchical structures closely packed with different building bricks have attracted considerable attention not only because of their high surface-to-volume ratios for the improvement of photocatalytic activity but also because of the large size of the complete structures for enhancing of separation efficiency $[13,14]$. Therefore, it is still scientific importance to explore novel $3 \mathrm{D} \mathrm{TiO}_{2}$ microspheres with visible light activity and high separation efficiency [15]. In this paper, we report a hydrothermal approach for the synthesis of hydrangea-like F-doped $\mathrm{TiO}_{2}$ microspheres. The as-prepared products were then characterized by XRD, SEM, TEM, and XPS techniques. The photocatalytic activities of the products before and after calcination at $500^{\circ} \mathrm{C}$ were evaluated by photocatalytic degradation of carbamazepine under UV and light-emitting diode (LED) light irradiation.

\section{Experimental Procedures}

Typically, $0.7 \mathrm{~g}$ of potassium titanium oxalate was dissolved in $15 \mathrm{~mL}$ of distilled water, then $15 \mathrm{~mL}$ of $30 \% \mathrm{H}_{2} \mathrm{O}_{2}, 0.4 \mathrm{~mL}$ of $37 \% \mathrm{HCl}$, and $400 \mathrm{mg}$ of $\mathrm{NH}_{4} \mathrm{~F}$ is added to the solution. After five minutes of stirring, the final mixture was directly transferred into a $50 \mathrm{~mL}$ Teflon-lined stainless autoclave. The autoclave was maintained at $140^{\circ} \mathrm{C}$ for $24 \mathrm{~h}$ and afterwards allowed to cool to room temperature naturally. Finally, the 


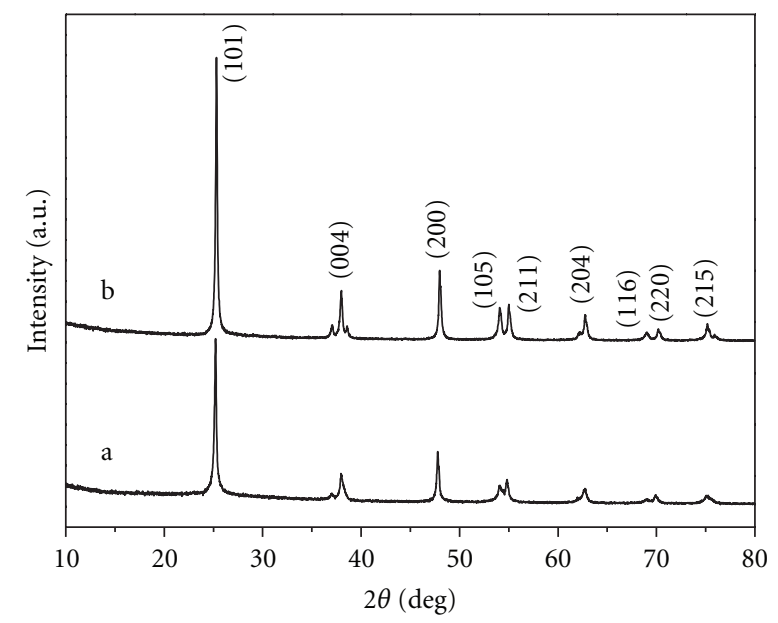

a: Without calcination

b: Calcination at $500^{\circ} \mathrm{C}$

FIGURE 1: XRD patterns of the as-prepared hydrangea-like F-doped $\mathrm{TiO}_{2}$ microspheres before and after calcinations at $500^{\circ} \mathrm{C}$.

white precipitate was collected, washed with distilled water and ethanol three times, respectively, then dried at $80^{\circ} \mathrm{C}$ for $12 \mathrm{~h}$, and calcined in air at $500^{\circ} \mathrm{C}$ for $2 \mathrm{~h}$.

The crystalline structure of the sample was characterized by X-ray diffraction (XRD) with $\mathrm{Cu} \mathrm{K} \alpha$ radiation $(\lambda=$ $1.5406 \AA$ ). The size and morphology of the sample were analyzed using a scanning electron microscopy (SEM, Hitachi S-4800) and a transmission electron microscopy (TEM, Phillips Tecnai 10) with an accelerating voltage of $100 \mathrm{kV}$. The BET surface area and pore size distribution of the product were measured by $\mathrm{N}_{2}$ adsorption-desorption test (Quantachrome, ASIC-2 measuring instrument). The UVvisible absorption diffuse reflectance spectra were measured on a TU-1901 spectrophotometer equipped with a labsphere diffuse reflectance accessory. The X-ray photoelectron spectroscopy (XPS) measurements were carried out using a VG ESCA Lab Mark II system with Mg K $\alpha$ excitation.

Photocatalytic degradation of carbamazepine under UV and blue LED light irradiation was carried out in a Pyrex cylindrical batch photoreactor (containing $400 \mathrm{~mL}$ reaction slurry, as shown in previous work [2]) and a $100 \mathrm{~mL}$ beaker (containing $80 \mathrm{~mL}$ reaction slurry, as shown previously [16]), respectively. Agitation was provided by magnetic stirrer. The aqueous slurry, prepared with a given amount of catalyst $1.0 \mathrm{~g} / \mathrm{L}$ and carbamazepine in concentration of $0.1 \times$ $10^{-5} \mathrm{~mol} / \mathrm{L}$, was stirred in the dark for $30 \mathrm{~min}$ to ensure that the carbamazepine was adsorbed to saturation on the catalysts. A 10 W UV lamp (254 nm, GPH212T5L/4, Germany) and a 3 W blue LED lamp ( $470 \mathrm{~nm}$, Exploit 220024, China) were used as UV and visible light source, respectively.

The concentration of carbamazepine was determined by HPLC (Agilent 1200, USA) provided with a UV-Vis detector. A $4.6 \mathrm{~mm} \times 250 \mathrm{~mm}(5 \mu \mathrm{m})$ XDB-C18 column was used. The analysis was carried out isocratically with an $60 / 40(\mathrm{v} / \mathrm{v})$ methanol/water mobile phase, and the flow rate was set at $1.0 \mathrm{~mL} / \mathrm{min}$.

\section{Results and Discussion}

The XRD patterns of the hydrangea-like F-doped $\mathrm{TiO}_{2}$ microspheres before and after calcinations at $500^{\circ} \mathrm{C}$ for $2 \mathrm{~h}$ are shown in Figure 1. Before calcination, the strong and sharp diffraction peaks indicate that the uncalcined products are well crystalline. All diffraction peaks can be perfectly indexed to the anatase phase of $\mathrm{TiO}_{2}$ (JCPDS 21-1272). No characteristic peaks of other impurities are detected in the XRD pattern, indicating that the F-doped $\mathrm{TiO}_{2}$ microspheres with high purity could be obtained under current facile synthetic conditions. Calcination at $500^{\circ} \mathrm{C}$ for $2 \mathrm{~h}$ does not change the phase and composition of the hydrangea-like Fdoped $\mathrm{TiO}_{2}$ microspheres.

The morphologies and microstructures of the hydrangea-like F-doped $\mathrm{TiO}_{2}$ microspheres were characterized by scanning electron microscopy (SEM). Figure 2(a) shows a low-magnification SEM image of the as-prepared sample, which performs that the products consist of large-scale microspheres. The average external diameter of the microspheres is $2.85 \mu \mathrm{m}$, as observed by measuring 100 microspheres. A high-magnification SEM image (Figure 2(b)) reveals that the as-prepared products are hydrangea-like with many randomly attached petal-like structures. Moreover, the surface of the petal is not smooth but is composed of numerous $\mathrm{TiO}_{2}$ nanoparticles (as shown in Figure 2(c)). The morphology and the size of the hydrangea-like $\mathrm{TiO}_{2}$ microspheres remain unchanged, while it was calcined at $500^{\circ} \mathrm{C}$ for $2 \mathrm{~h}$ (see Figures $2(d)-2(f))$. The typical TEM images of the hydrangea-like microspheres before and after calcination at $500^{\circ} \mathrm{C}$ for $2 \mathrm{~h}$ are shown in Figure 3, and it is clear that the microsphere is solid with an external diameter of about $2.87 \mu \mathrm{m}$, which is in agreement with the SEM observation.

It has been found that both $\mathrm{NH}_{4} \mathrm{~F}$ and $\mathrm{H}_{2} \mathrm{O}_{2}$ play important roles in the formation of the hydrangea-like structures. Without any addition of $\mathrm{NH}_{4} \mathrm{~F}$ and $\mathrm{H}_{2} \mathrm{O}_{2}$, no precipitation can be obtained. Increasing $\mathrm{H}_{2} \mathrm{O}_{2}$ dosage to $15 \mathrm{mg}$ without 


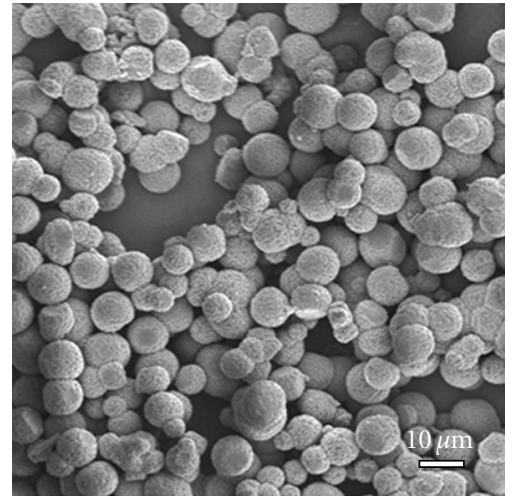

(a)

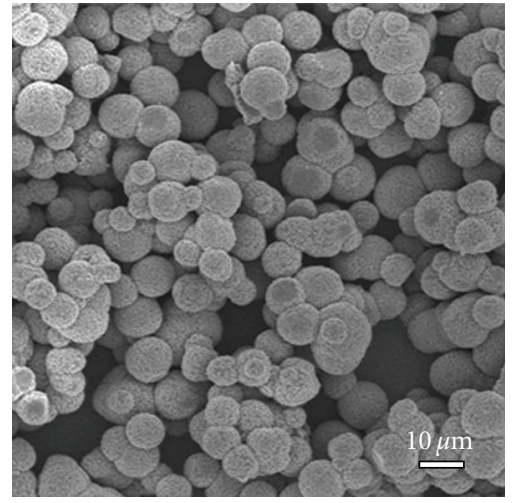

(d)

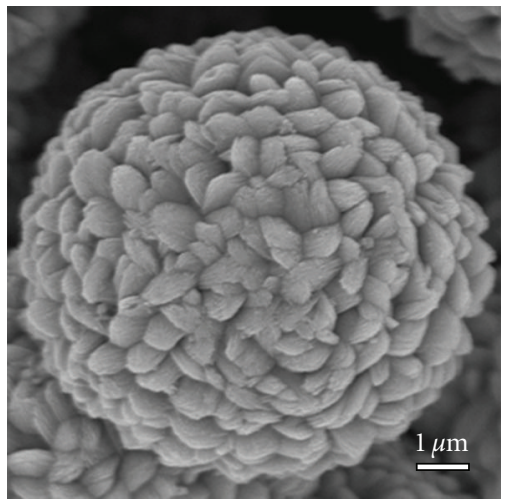

(b)

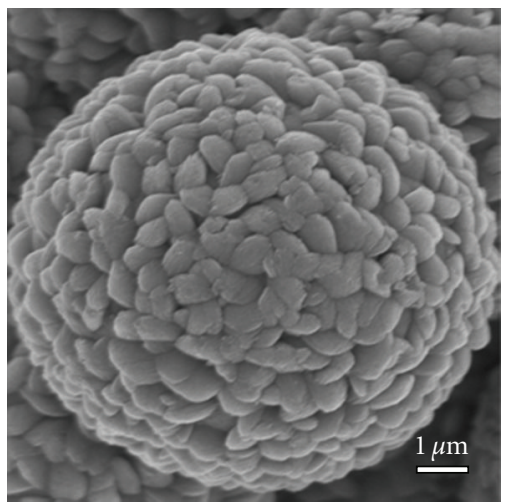

(e)

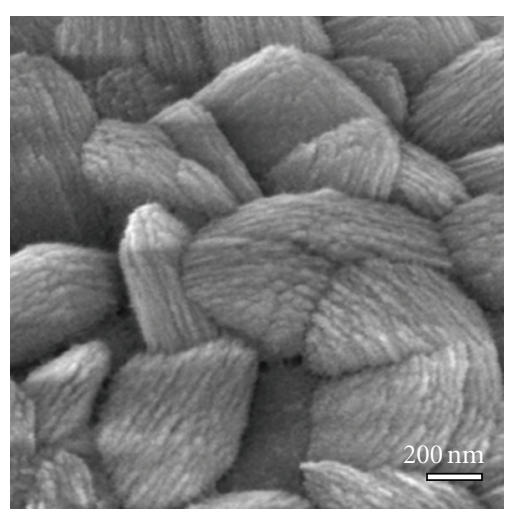

(c)

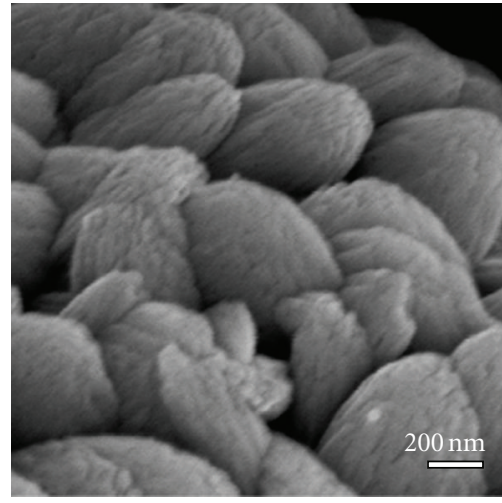

(f)

FIgURE 2: SEM images of the hydrangea-like F-doped $\mathrm{TiO}_{2}$ microspheres (a, b, c) before and (d, e, f, ) after calcinations at $500^{\circ} \mathrm{C}$.

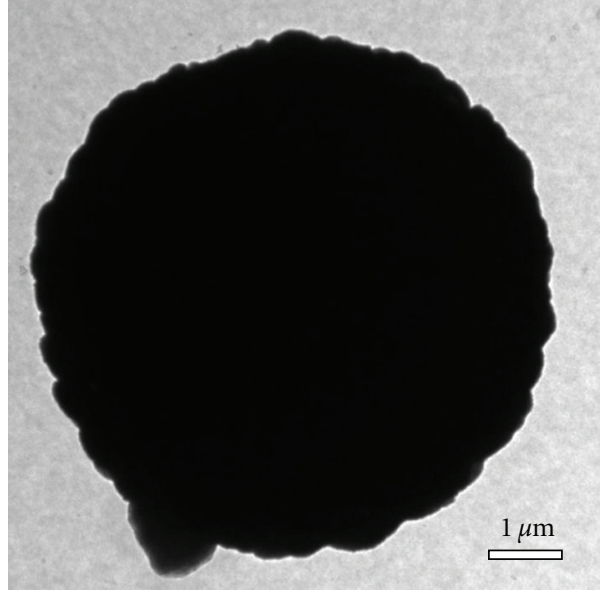

(a)

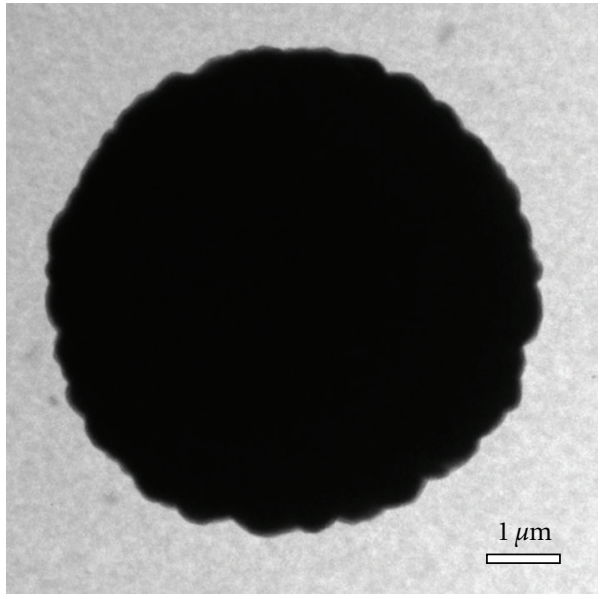

(b)

Figure 3: TEM images of the hydrangea-like F-doped $\mathrm{TiO}_{2}$ microspheres (a) before and (b) after calcinations at $500^{\circ} \mathrm{C}$.

adding any $\mathrm{NH}_{4} \mathrm{~F}$, only aggregated nanoparticles can be observed. These two experiments indicate that the formation of hydrangea-like microspheres can be attributed to the HF generated during the hydrothermal process [17]. In addition, it has been found that microspheres closely packed with needle-like nanostructures could still be obtained when $\mathrm{NH}_{4} \mathrm{~F}$ was replaced by $\mathrm{NaF}$, while no microspheres could be produced when $\mathrm{NH}_{4} \mathrm{Cl}$ was used. This further confirms the crucial role of HF for the formation of hydrangea-like microspheres (see Figures 4(a) and 4(b)). Furthermore, the 


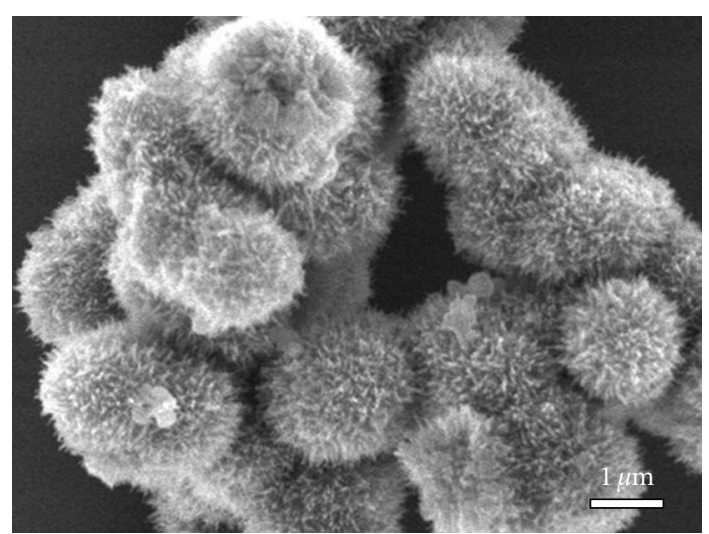

(a)

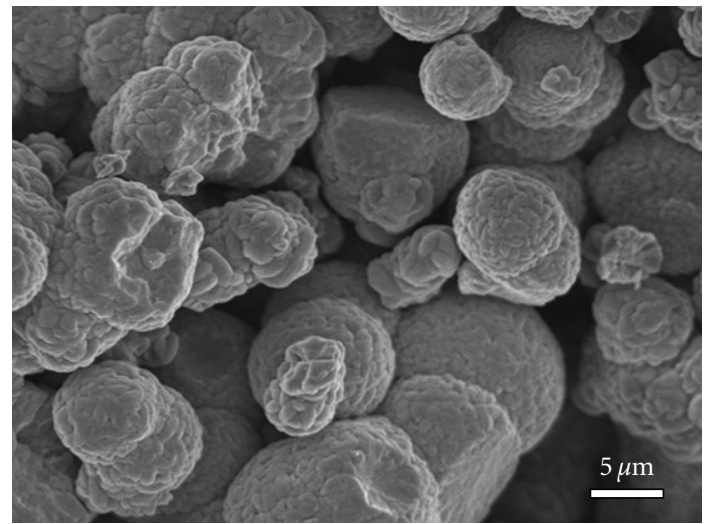

(c)

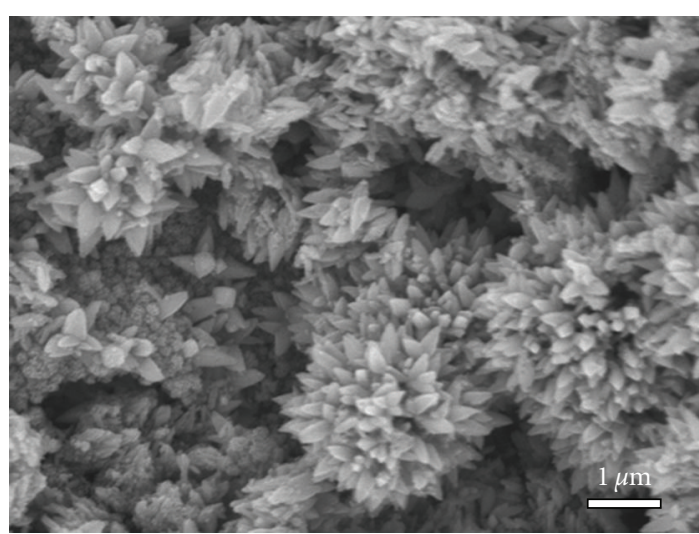

(b)

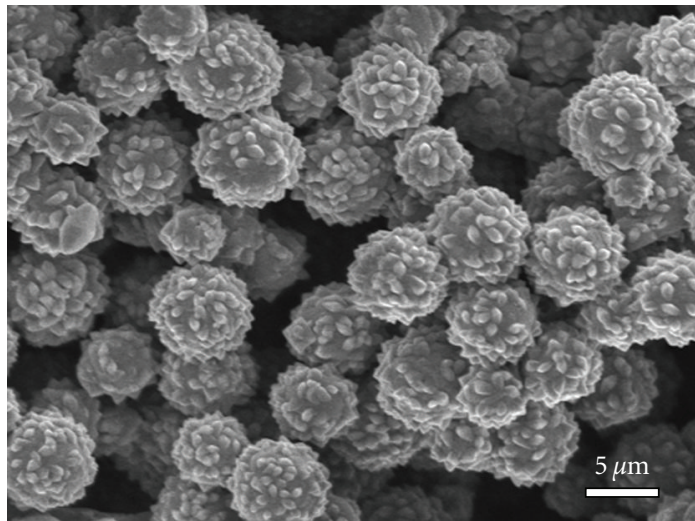

(d)

FIGURE 4: SEM images of the as-prepared samples prepared hydrothermally (a) replaced $\mathrm{NH}_{4} \mathrm{~F}$ by $\mathrm{NaF},(\mathrm{b})$ replaced $\mathrm{NH}_{4} \mathrm{~F}$ by $\mathrm{NH}_{4} \mathrm{Cl}$, (c) $10 \mathrm{~mL}$ of $\mathrm{H}_{2} \mathrm{O}_{2}$, and (d) $30 \mathrm{~mL}$ of $\mathrm{H}_{2} \mathrm{O}_{2}$ under the same conditions as those of the hydrangea-like F-doped $\mathrm{TiO}_{2}$ microspheres.

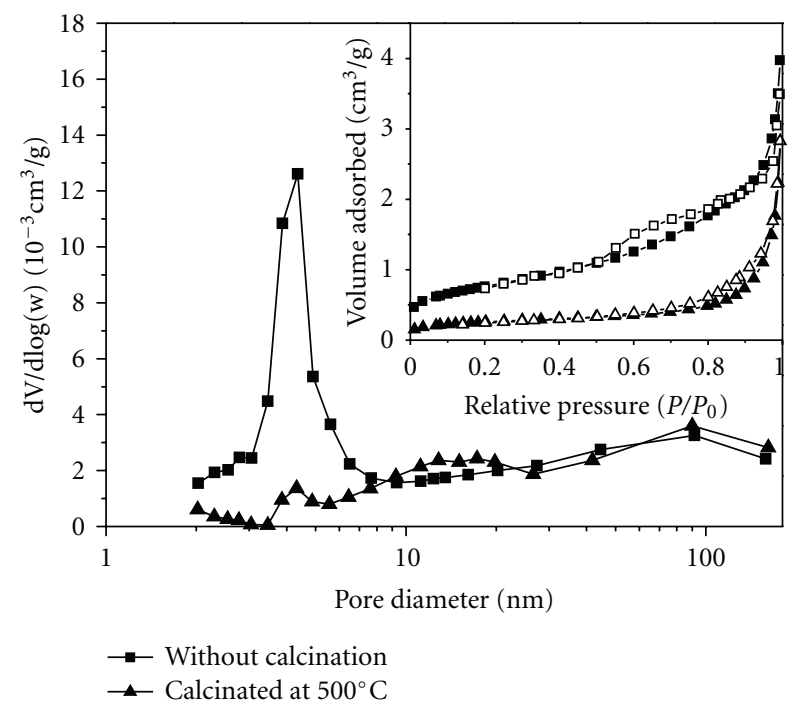

Figure 5: (a) Nitrogen adsorption-desorption isotherm and (b) $\mathrm{BJH}$ pore-size distribution curve of the hydrangea-like F-doped $\mathrm{TiO}_{2}$ microspheres before and after calcinations at $500^{\circ} \mathrm{C}$.

hydrangea-like microspheres could only be obtained when suitable amount of $\mathrm{H}_{2} \mathrm{O}_{2}$ was added in the reaction system (as shown in Figures 4(c) and 4(d)).

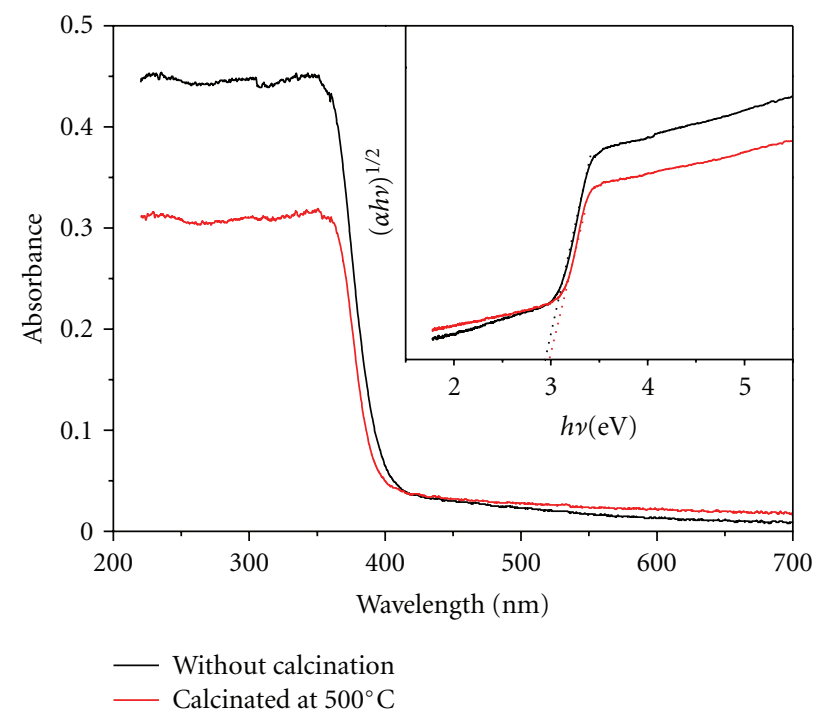

FIGURE 6: UV-vis absorbance spectra of the hydrangea-like F-doped $\mathrm{TiO}_{2}$ microspheres before and after calcination. The inset shows the plot of $(\alpha h \nu)^{1 / 2}$ versus the $(h \nu)$.

Figure 5(a) shows the nitrogen adsorption-desorption isotherms of the hydrangea-like $\mathrm{F}$-doped $\mathrm{TiO}_{2}$ microspheres before and after calcinations at $500^{\circ} \mathrm{C}$. Before calcination, the 


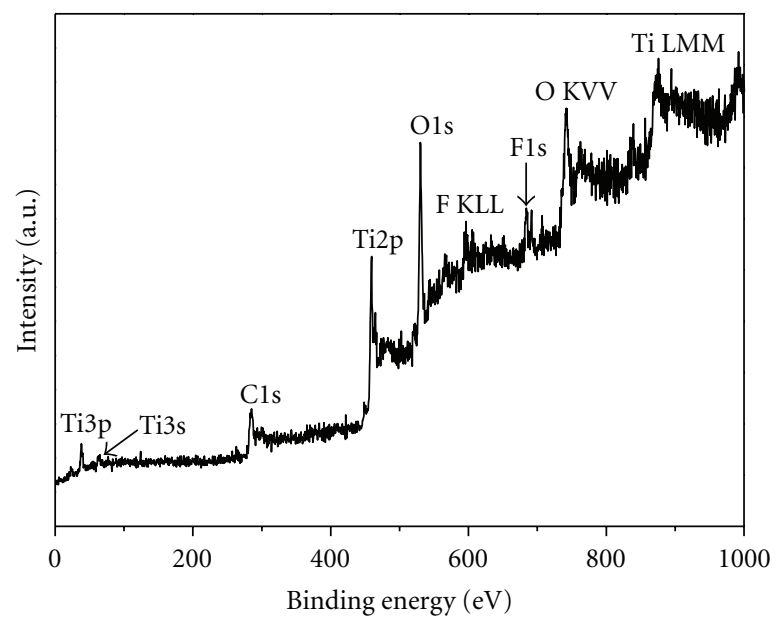

(a)

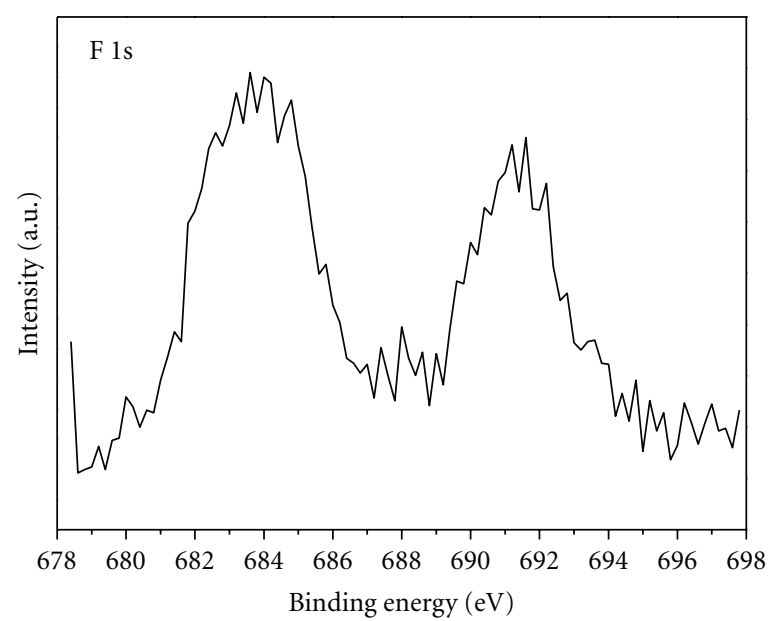

(b)

Figure 7: (a) XPS survey spectra and (b) high-resolution XPS spectra of the F 1s region taken on the hydrangea-like F-doped TiO ${ }_{2}$ microspheres.

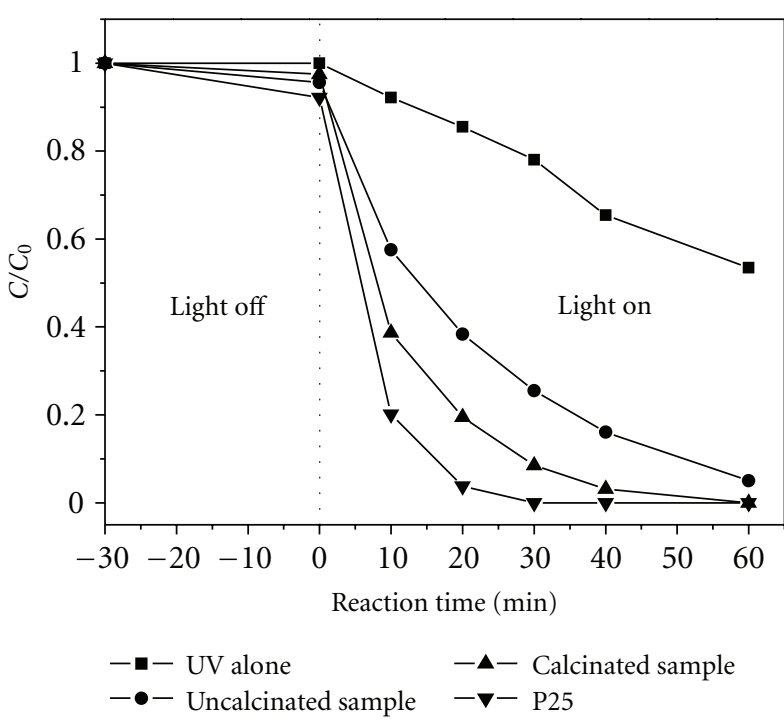

(a)

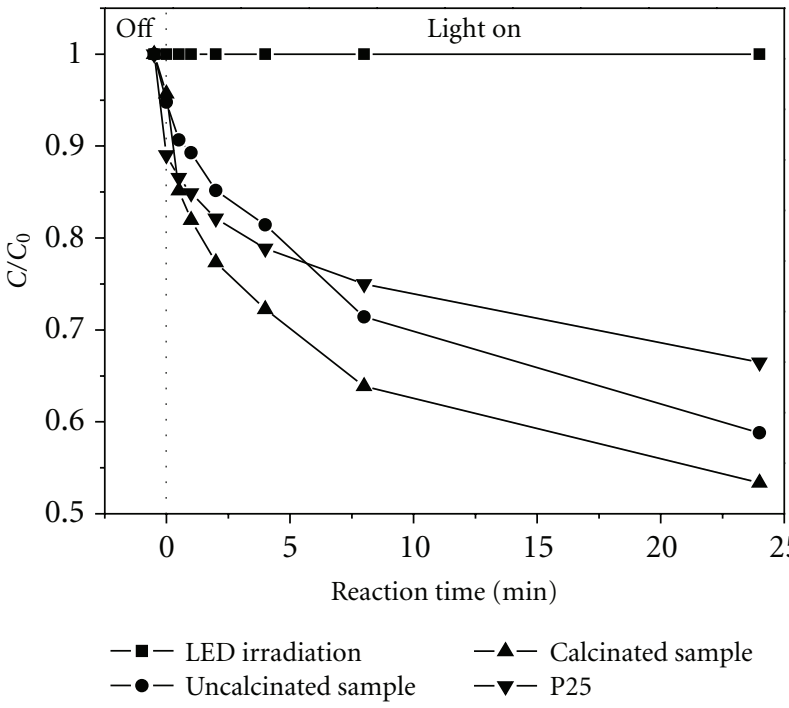

(b)

FIGURE 8: Photodegradation of carbamazepine under (a) UV and (b) blue LED light irradiation.

isotherms are of the typical type IV pattern with distinct $\mathrm{H}_{2}$ and $\mathrm{H}_{3}$ hysteretic loops in the range of $0.4-0.9 \mathrm{P} / \mathrm{P}_{0}$ and $0.9-$ $1.0 \mathrm{P} / \mathrm{P}_{0}$, respectively, indicating the existence of ink-bottle and slit-shaped pores according to the IUPAC classification [18]. It has been pointed out that the bimodal pores are beneficial to the enhancement of photocatalytic performance due to faster diffusion of various reactants and byproducts [19]. After calcinations at $500^{\circ} \mathrm{C}$, the hysteresis loops shifted to a higher relative pressure $\left(\mathrm{P} / \mathrm{P}_{0}\right)$ range and the area of the hysteresis loops gradually became smaller. This indicates the increase of average pore size and the decrease of pore volume [20]. The corresponding pore size distribution of the hydrangea-like F-doped $\mathrm{TiO}_{2}$ microspheres (see Figure 5(b)) was determined using the Barrett-Joyner-Halenda (BJH) method from the desorption branch of the isotherm. The BET surface area and average pore diameter of the hydrangea-like F-doped $\mathrm{TiO}_{2}$ microspheres before and after calcination are $2.74 \mathrm{~m}^{2} / \mathrm{g}$ and $8.0 \mathrm{~nm}, 1.03 \mathrm{~m}^{2} / \mathrm{g}$, and $20.5 \mathrm{~nm}$, respectively.

The optical band gaps of hydrangea-like F-doped $\mathrm{TiO}_{2}$ microspheres before and after calcination were studied by the UV-vis optical absorbance spectrum. The relationship between the absorption coefficient $(\alpha)$ and the photon energy $(h v)$ can be written as shown in (1) [21]:

$$
(a h v)^{n}=B\left(E-E_{g}\right),
$$

where $B$ is the constant related to the effective masses associated with the valence and conduction bands, $E=h v$ is the 


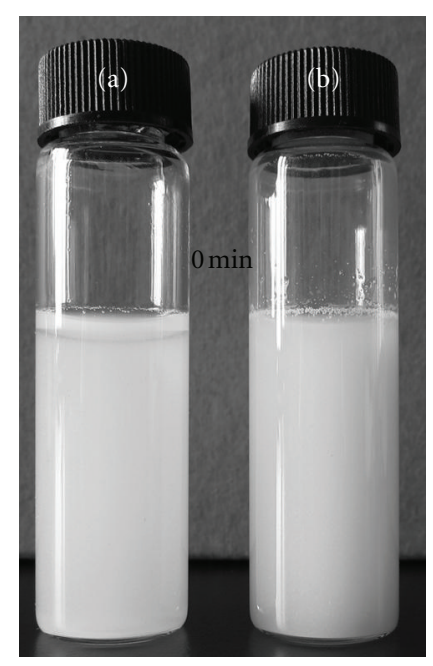

(a)

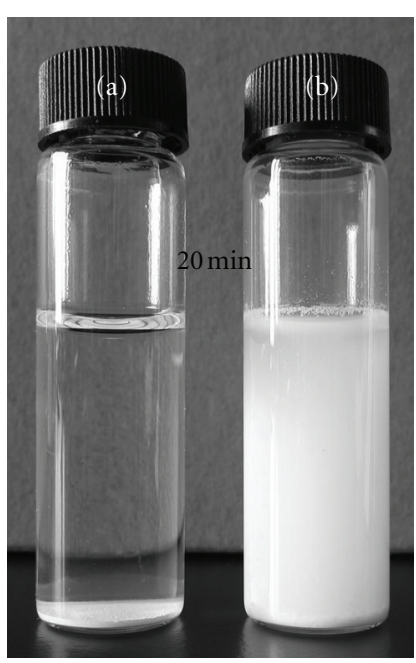

(b)

FIgURE 9: Sedimentation for $20 \mathrm{~min}$ in aqueous suspensions of (a) hydrangea-like titania microspheres and (b) Degussa P25.

photon energy, $E_{g}$ is the band gap energy, and $n=1 / 2$ or 2 , depending on whether the transition is indirect or direct. Figure 6 shows the absorption spectra of the hydrangealike F-doped $\mathrm{TiO}_{2}$ microspheres before and after calcination. The inset shows the plots of $(\alpha h v)^{1 / 2}$ versus the $(h v)$. The band gap energy $\left(E_{g}\right)$ for the samples can be calculated by extrapolating the linear portion of $(\alpha h \nu)^{1 / 2}$ versus the $(h \nu)$ plot to $\alpha=0$. On the basis of these results, the optical band gaps for the products before and after calcinations are 2.92 and 2.97, respectively, which are lower than that of Degussa $\mathrm{P} 25 \mathrm{TiO}_{2}\left(E_{g}=3.18-3.28 \mathrm{eV}[22,23]\right)$. The slight redshift of the optical band gap might be the result of $\mathrm{F}^{-}$anions successfully doped in the hydrangea-like $\mathrm{TiO}_{2}$ microspheres $[8,24]$.

X-ray photoelectron spectroscopy (XPS) measurements were carried out to confirm the chemical compositions and the existence forms of the elements in the F-doped $\mathrm{TiO}_{2}$ microspheres. The results are shown in Figure 7. In the spectrum, elements of Ti, F, O, and C can be observed. The $\mathrm{C} 1 \mathrm{~s}$ at $284.6 \mathrm{eV}$ is due to the adventitious hydrocarbon originated from the instrument itself. Figure 7(b) gives the high resolution XPS spectra of $F$ 1s regions from the surfaces of the sample. It can be seen that there are two kinds of $F$ states observed in the F 1s XPS spectrum. The low binding energy of around $683.8 \mathrm{eV}$ could be ascribed to the $\mathrm{F}^{-}$anions physically adsorbed on the surface of $\mathrm{TiO}_{2}$, while the high binding energy located at $691.2 \mathrm{eV}$ could be ascribed to the $\mathrm{F}$ atoms substituting for the $\mathrm{O}$ atoms, forming the Ti-F bonds $[8,25]$.

Figure $8(\mathrm{a})$ shows the degradation curves of carbamazepine as a function of reaction time in the presence of different photocatalysts under UV light irradiation. The removal rate dramatically increases with the addition of calcinated F-doped $\mathrm{TiO}_{2}$ microspheres, which is comparable to that of well-known commercial photocatalyst Degussa P25. The good photocatalytic activity of the products may be caused by the following three factors. First, the physically adsorbed $\mathrm{F}^{-}$anions on the surface of $\mathrm{TiO}_{2}$ can increase the photocatalytic degradation efficiency since the $\cdot \mathrm{OH}$ radicals generated on $\mathrm{F}-\mathrm{TiO}_{2}$ surface are more mobile than those generated on pure $\mathrm{TiO}_{2}$ under UV irradiation $[8,26,27]$. Second, the enhancement of anatase crystallization can accelerate the transmission rate of photogenerated electrons and holes, and thus the photocatalytic activity of $\mathrm{TiO}_{2}$ is improved [28]. Third, the unique nanostructures are beneficial to the enhancement of photocatalytic performance due to faster diffusion of the reactant and byproducts [14].

The degradation curves of carbamazepine in the presence of hydrangea-like F-doped $\mathrm{TiO}_{2}$ microspheres before and after calcination under blue LED light $(\sim 470 \mathrm{~nm})$ irradiation are shown in Figure 8(b). It has been found that LED light irradiation has no effect on the carbamazepine removal, no more than $0.5 \%$ of carbamazepine could be decomposed even after $24 \mathrm{~h}$ irradiation. It can also be seen that under identical conditions, the calcinated F-doped $\mathrm{TiO}_{2}$ microspheres possesses the highest removal efficiency. Though the removal rate of carbamazepine is only $46.7 \%$ at the reaction time of $24 \mathrm{~h}$, the use of LED as the light source will make the application of heterogeneous photocatalysis practical since LED is now widely used in daily life.

Microspheres have taken an advantage over powder catalysts for separating the catalyst from solution by filtration or sedimentation. In our experimental, the $\mathrm{TiO}_{2}$ hollow microspheres can be separated from an aqueous suspension in less than $4 \mathrm{~h}$ by sedimentation (as shown in Figure 9), while the aqueous suspension of Degussa P25 is still turbid even after several days.

\section{Conclusions}

In summary, we report the hydrothermal synthesis of hydrangea-like F-doped $\mathrm{TiO}_{2}$ microspheres without using any templates or surfactants. It has been found that both of the $\mathrm{NH}_{4} \mathrm{~F}$ and $\mathrm{H}_{2} \mathrm{O}_{2}$ dosages have important effects on the 
formation of the hydrangea-like structures. The hydrangealike F-doped $\mathrm{TiO}_{2}$ microspheres calcined at $500^{\circ} \mathrm{C}$ exhibits higher photocatalytic activity than that of Degussa P25 under both UV and visible light irradiation. The enhanced photocatalytic activity can be attributed to the successful fluorine doping, good crystallinity, and the unique nanostructures. In addition, the use of LED as the light source will make the application of heterogeneous photocatalysis in practice possible.

\section{Acknowledgments}

This work was financially supported by the National Natural Science Foundation of China (Grant no. 51108406) and the Fundamental Research Funds for the Central Universities (2011FZA4022), to the authors we are grateful.

\section{References}

[1] A. Markowska-Szczupak, K. Ulfig, and A. W. Morawski, “The application of titanium dioxide for deactivation of bioparticulates: an overview," Catalysis Today, vol. 169, no. 1, pp. 249257, 2011.

[2] M. Ye, Z. Chen, X. Liu, Y. Ben, and J. Shen, "Ozone enhanced activity of aqueous titanium dioxide suspensions for photodegradation of 4-chloronitrobenzene," Journal of Hazardous Materials, vol. 167, no. 1-3, pp. 1021-1027, 2009.

[3] Y. P. Guo, S. G. Yang, X. F. Zhou, C. Lin, Y. J. Wang, and W. F. Zhang, "Enhanced photocatalytic activity for degradation of methyl orange over silica-titania," Journal of Nanomaterials, vol. 2011, Article ID 296953, 9 pages, 2011.

[4] S. Sakthivel, M. Janczarek, and H. Kisch, "Visible light activity and photoelectrochemical properties of nitrogen-doped $\mathrm{TiO}_{2}$," Journal of Physical Chemistry B, vol. 108, no. 50, pp. 19384-19387, 2004.

[5] S. Livraghi, M. C. Paganini, E. Giamello, A. Selloni, C. Di Valentin, and G. Pacchioni, "Origin of photoactivity of nitrogen-doped titanium dioxide under visible light," Journal of the American Chemical Society, vol. 128, no. 49, pp. 15666-15671, 2006.

[6] H. Yang and X. Zhang, "Synthesis, characterization and computational simulation of visible-light irradiated fluorinedoped titanium oxide thin films," Journal of Materials Chemistry, vol. 19, no. 37, pp. 6907-6914, 2009.

[7] J. Ryu and W. Choi, "Effects of $\mathrm{TiO}_{2}$ surface modifications on photocatalytic oxidation of arsenite: the role of superoxides," Environmental Science and Technology, vol. 38, no. 10, pp. 2928-2933, 2004.

[8] J. C. Yu, J. Yu, W. Ho, Z. Jiang, and L. Zhang, "Effects of Fdoping on the photocatalytic activity and microstructures of nanocrystalline $\mathrm{TiO}_{2}$ powders," Chemistry of Materials, vol. 14, no. 9, pp. 3808-3816, 2002.

[9] Q. Xiang, J. Yu, and M. Jaroniec, “Tunable photocatalytic selectivity of $\mathrm{TiO}_{2}$ films consisted of flower-like microspheres with exposed 001 facets," Chemical Communications, vol. 47, no. 15, pp. 4532-4534, 2011.

[10] S. Liu, J. Yu, and M. Jaroniec, "Anatase $\mathrm{TiO}_{2}$ with dominant high-energy 001 facets: synthesis, properties, and applications," Chemistry of Materials, vol. 23, no. 18, pp. 4085-4093, 2011.

[11] Y. Xie, Y. Li, and X. Zhao, "Low-temperature preparation and visible-light-induced catalytic activity of anatase F-N-codoped
$\mathrm{TiO}_{2}$," Journal of Molecular Catalysis A, vol. 277, no. 1-2, pp. 119-126, 2007.

[12] H. Park and W. Choi, "Effects of $\mathrm{TiO}_{2}$ surface fluorination on photocatalytic reactions and photoelectrochemical behaviors," Journal of Physical Chemistry B, vol. 108, no. 13, pp. 40864093, 2004.

[13] X. Z. Li, H. Liu, L. F. Cheng, and H. J. Tong, "Photocatalytic oxidation using a new catalyst- $\mathrm{TiO}_{2}$ microsphere-For water and wastewater treatment," Environmental Science and Technology, vol. 37, no. 17, pp. 3989-3994, 2003.

[14] J. Yu, H. Guo, S. A. Davis, and S. Mann, "Fabrication of hollow inorganic microspheres by chemically induced selftransformation," Advanced Functional Materials, vol. 16, no. 15, pp. 2035-2041, 2006.

[15] J. H. Pan, X. Zhang, A. J. Du, D. D. Sun, and J. O. Leckie, "Selfetching reconstruction of hierarchically mesoporous $\mathrm{F}-\mathrm{TiO}_{2}$ hollow microspherical photocatalyst for concurrent membrane water purifications," Journal of the American Chemical Society, vol. 130, no. 34, pp. 11256-11257, 2008.

[16] M. M. Ye, Q. Zhang, Y. X. Hu et al., "Magnetically recoverable core-shell nanocomposites with enhanced photocatalytic activity," Chemistry, vol. 16, no. 21, pp. 6243-6250, 2010.

[17] M. Ye, Y. Yang, T. Zhang, Y. Shao, and C. Li, “Template-free hydrothermal synthesis of macroporous $\mathrm{TiO}_{2}$ microspheres on a large scale," Materials Letters, vol. 65, no. 15-16, pp. 23842387, 2011.

[18] K. S. W. Sing, D. H. Everett, R. A. W. Haul et al., "Reporting physisorption data for gas solid systems with special reference to the determination of surface-area and porosity," Pure and Applied Chemistry, vol. 57, no. 4, pp. 603-619, 1985.

[19] Y. Chen and D. D. Dionysiou, "Bimodal mesoporous $\mathrm{TiO}_{2}$ P25 composite thick films with high photocatalytic activity and improved structural integrity," Applied Catalysis B, vol. 80, no. 1-2, pp. 147-155, 2008.

[20] J. Yu, M. Zhou, B. Cheng, and X. Zhao, "Preparation, characterization and photocatalytic activity of in situ N,S-codoped $\mathrm{TiO}_{2}$ powders," Journal of Molecular Catalysis A, vol. 246, no. 1-2, pp. 176-184, 2006.

[21] N. Serpone, D. Lawless, and R. Khairutdinov, "Size effects on the photophysical properties of colloidal anatase $\mathrm{TiO}_{2}$ particles: size quantization or direct transitions in this indirect semiconductor?" Journal of Physical Chemistry, vol. 99, no. 45, pp. 16646-16654, 1995.

[22] M. Ye, Z. Chen, W. Wang, J. Shen, and J. Ma, "Hydrothermal synthesis of $\mathrm{TiO}_{2}$ hollow microspheres for the photocatalytic degradation of 4-chloronitrobenzene," Journal of Hazardous Materials, vol. 184, no. 1-3, pp. 612-619, 2010.

[23] Z. Liu, D. D. Sun, P. Guo, and J. O. Leckie, "One-step fabrication and high photocatalytic activity of porous $\mathrm{TiO}_{2}$ hollow aggregates by using a low-temperature hydrothermal method without templates," Chemistry, vol. 13, no. 6, pp. 1851-1855, 2007.

[24] G. Yang, Z. Jiang, H. Shi et al., "Study on the photocatalysis of F-S co-doped $\mathrm{TiO}_{2}$ prepared using solvothermal method," Applied Catalysis B, vol. 96, no. 3-4, pp. 458-465, 2010.

[25] Y. huo, Y. jin, J. zhu, and H. li, "Highly active $\mathrm{TiO}_{2-x-y} \mathrm{~N}_{x} \mathrm{~F}_{y}$ visible photocatalyst prepared under supercritical conditions in $\mathrm{NH}_{4} \mathrm{~F} / \mathrm{EtOH}$ fluid," Applied Catalysis B, vol. 89, no. 3-4, pp. 543-550, 2009.

[26] J. Yu, W. Wang, B. Cheng, and B. L. Su, "Enhancement of photocatalytic activity of Mesporous $\mathrm{TiO}_{2}$ powders by hydrothermal surface fluorination treatment," Journal of Physical Chemistry C, vol. 113, no. 16, pp. 6743-6750, 2009. 
[27] S. Liu, J. Yu, and M. Jaroniec, “Tunable photocatalytic selectivity of hollow $\mathrm{TiO}_{2}$ microspheres composed of anatase polyhedra with exposed 001 facets," Journal of the American Chemical Society, vol. 132, no. 34, pp. 11914-11916, 2010.

[28] J. Yu, L. Zhang, B. Cheng, and Y. Su, "Hydrothermal preparation and photocatalytic activity of hierarchically sponge-like macro-/mesoporous Titania," Journal of Physical Chemistry C, vol. 111, no. 28, pp. 10582-10589, 2007. 

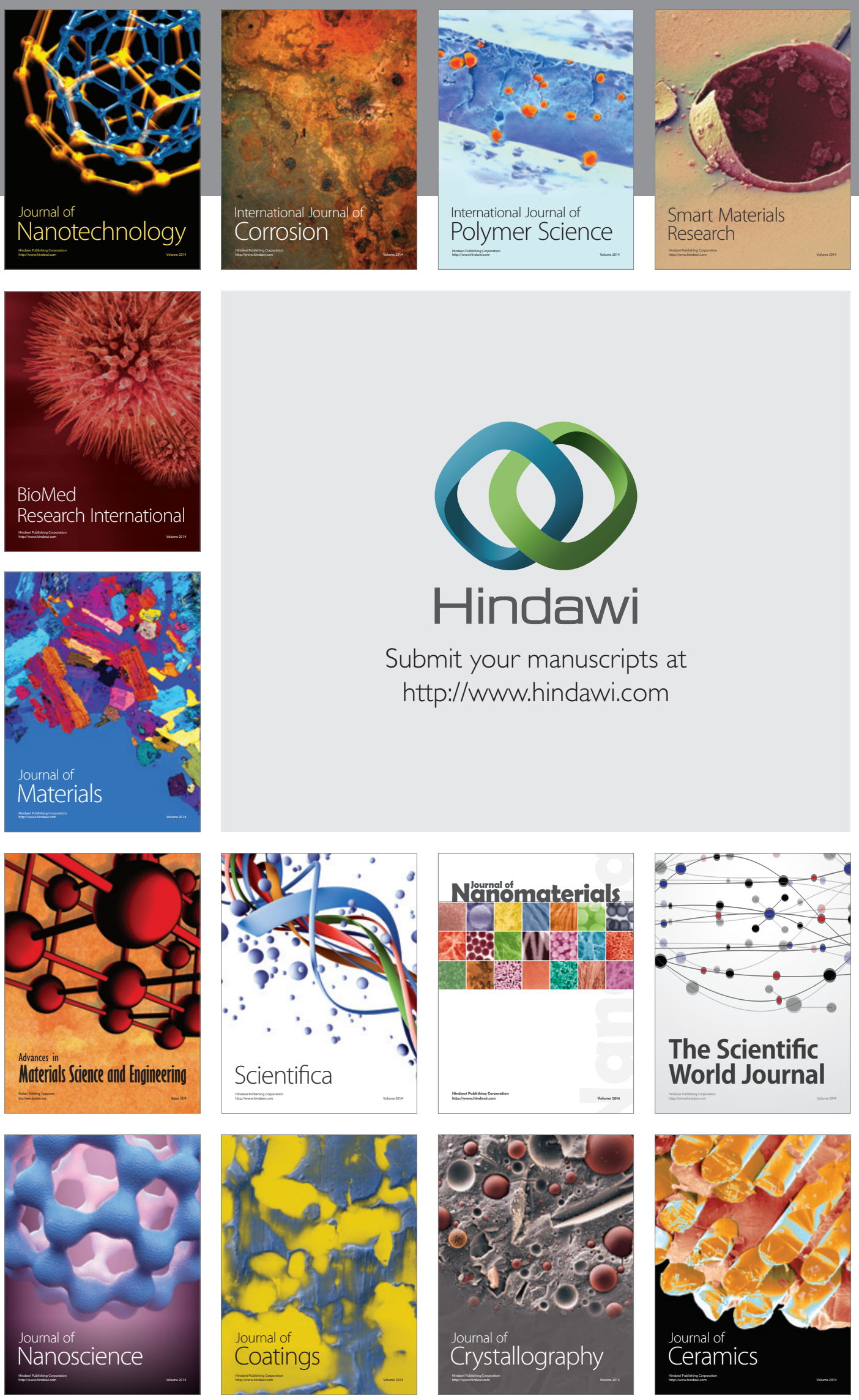

The Scientific World Journal

Submit your manuscripts at

http://www.hindawi.com

\section{World Journal}

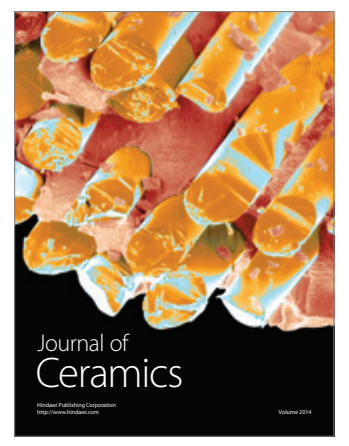

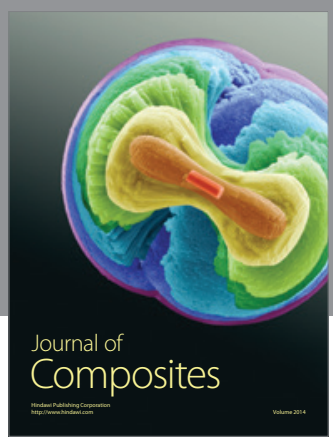
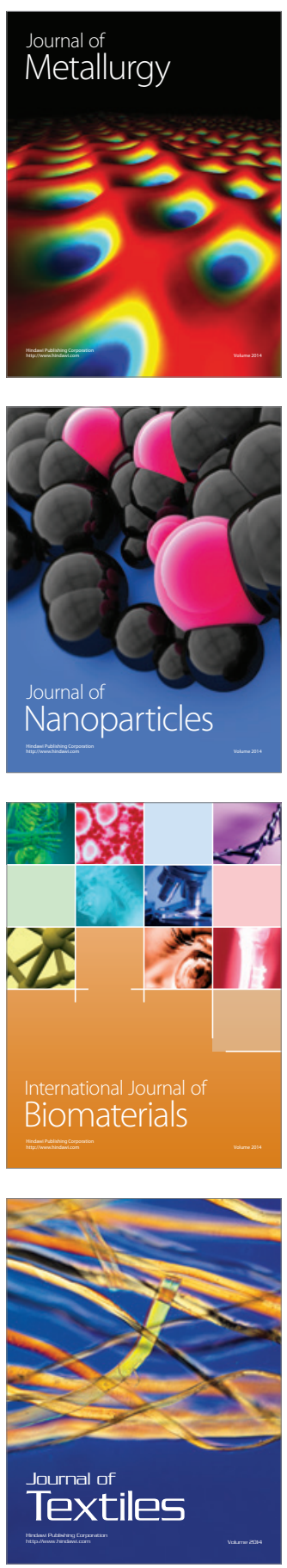